\title{
Assessment of impact of construction materials on the ecological safety of home
}

\author{
Anna Zhigulina ${ }^{1,{ }^{*}, \text { Natalia Chumachenko }}{ }^{1}$ \\ ${ }^{1}$ Samara State Technical University, Institute of Architecture and Civil Engineering, 194 \\ Molodogvardeyskaya St., 443001, Samara, Russia
}

\begin{abstract}
The article deals with the problems of creating environmentally friendly aerial environment within residential premises. The main sources causing air pollution of urban housing are determined and classified. The origins of air pollution sources of residential premises are adopted as the classifying criterion. The sources of contamination are defined and assessed. Particular attention is paid to the choice of environmentally friendly building materials. The methodology for assessing toxicity of industrial waste used in the production of housing materials is developed to assess the comfort and environmental safety of home. The idea of creating "Residential buldings ID" containing information on the construction materials used is introduced.
\end{abstract}

\section{Introduction}

Collaborative studies of hygienists, architects and builders in the course of design and construction of housing in the USSR rendered it possible to realistically assess the quality of the residential premises environment, to introduce necessary adjustments and updates to the construction regulation norms and thus produce healthy housing [1-7]. Such cooperation is just as essential now, when residential construction is done not only within government contracts, but on a commercial basis as well. Today, of course, environmental, sanitary and health departments, including the Academy of Medical Sciences, are actively working to create healthy living environment, they control the quality of building materials, are involved in the assessment of environmental conditions of residential premises, monitor air quality, water bodies, soil [8 -10]. Some of the authors [11-17] have focused on the issues of environmentally friendly housing design.

However, there are a number of topical issues concerning ecology and hygiene of residential buildings that deserve special attention from both the sanitary, engineering and construction companies, as well as the manufacturers of building materials.

\section{Materials and Methods}

According to the World Health Organization experts, city dwellers spend about $80 \%$ of their time indoors. The results of various studies of air quality in an urban apartment have

* Corresponding author: auzhigulina @, mail.ru 
shown that the indoor air is 4-6 times as polluted and 6-8 times as toxic compared to outdoors. Hygienists believe that indoor air pollution can cause health problems of various levels of severity, from simple discomfort and headaches to severe allergic reactions, asthmatic symptoms or even cancer.

Sources of indoor air pollution can roughly be divided into five main groups (Table 1)

Sources of indoor air pollution

Table 1

\begin{tabular}{|c|l|l|}
\hline $\begin{array}{c}\text { Pollution } \\
\text { sources } \\
\text { groups }\end{array}$ & \multicolumn{1}{|c|}{ Pollution source } & \multicolumn{1}{|c|}{ Location } \\
\hline 1 & substances entering premises with polluted urban air & external sources \\
\hline 2 & anthropotoxins (toxic human waste) & internal sources \\
\hline 3 & $\begin{array}{l}\text { substances related to household activity (household } \\
\text { chemicals, cooking gas combustion products) }\end{array}$ & internal sources \\
\hline 4 & $\begin{array}{l}\text { microbial air pollution (biodeterioration of } \\
\text { construction units caused by fungus, mold) }\end{array}$ & internal sources \\
\hline 5 & toxins released from building materials. & internal sources \\
\hline
\end{tabular}

We give below a more detailed description of these major groups of pollutants.

Group 1.The main sources of urban air pollution and, as a consequence, of air in urban apartments, are motor vehicles, industrial plants and heating systems. Contamination occurs due to tailpipe and aerosol pollution. According to Health Care in Russian Federation magazine, in 2005 only $15 \%$ of the urban population in Russia lived in the areas with pollution levels within hygienic standards. With every year of increase in the number of cars, the level of tailpipe pollution grows only higher. Improvement in quality of urban air can be achieved by the town planning activities, such as landscape gardening and watering areas, i.e. arrangement of parks, gardens, artificial lakes, ensuring sufficient aeration. Elimination of harmful effects of industrial enterprises on residential areas should be achieved by reasonable functional zoning of urban areas. This involves the remoteness of industrial enterprises from residential areas, the establishment of sanitary buffer zones which size shall be appointed in accordance with the enterprise hazard level and adjusted in line with the wind rose. It is quite difficult to introduce dramatic changes to current urban planning. New construction areas offer more opportunities for air pollution reduction. In this case, the contamination of air entering the apartment from the outside may be reduced by city planning decisions at the blueprint stage.

Groups 2,3,4. Sources of pollution from the second, third and fourth groups may controlled by the residing people to a greater or lesser extent.

Group 5.Building and finishing materials make for one of the most significant internal sources of air pollution in residential premises. They are the source of $80 \%$ of chemicals detected in the air of urban residences [18]. Harmful substances may originate from raw materials used for the production of building supplies, or be the result of destructive processes occurring during building operation.

Ensuring environmental and hygienic safety of the dwelling, in terms of choosing building materials, should provide for the application of construction and decorative materials with minimal or no emission of toxic substances throughout the "product life cycle". The concept of "product life cycle", introduced in a series of ISO 14000 standards, suggests the cycle of "Production - Maintenance - Disposal" for building materials.

At present, the mineral resource base of the construction industry includes two types of raw materials: natural and man-made. If construction or decoration procedures utilize natural building materials such as wood or stone, or natural raw materials (clay, sand, 
limestone, chalk, etc.) are used for manufacturing building supplies, their environmental safety is almost out of question. But even in this case, monitoring radiation background of mineral stock may be worth the time.

However, synthetic and composite materials are the most commonly used in modern construction. The current state of natural resource base is such that, on the one hand, the depletion of natural conditioned raw materials takes place, and, on the other hand, the amount of man-made by-products while extracting and processing raw materials is constantly growing. Very often, industrial wastes are used as additives for various purposes, or substitutes of some natural raw materials in production of construction supplies. The development of industry in our country has led to formation of large amounts of waste, which harmful effect on the biosphere is beyond doubt. The establishment of cost-effective methods for their disposal, one of which is the use of industrial waste in production of building materials, is, by all means, a very important issue. The results obtained in the course of research, including those lead by scientists of Institute of Architecture and Civil Engineering of Samara State Technical University [19], confirm the prospects of this approach.

Although, waste recycling can be considered effective if both economic criteria and environmental properties of materials produced from waste are taken into account, which should eliminate harmful effects of wastes on human beings.

The toxicity of industrial waste needs to be assessed while determining the way of its application. The methodology for evaluating toxicity of waste by comparing the toxicity of industrial waste emission with MPC of carcinogenic (toxic) substances and elements has been developed. According to the methodology, the waste is divided into three types (cm табл.2)

Evaluation of industrial waste types in aspect of toxic ingredients content and applicability to building materials production

Table 2

\begin{tabular}{|c|l|l|}
\hline $\begin{array}{c}\text { Industrial } \\
\text { waste type }\end{array}$ & \multicolumn{1}{|c|}{ Toxic ingredients content } & $\begin{array}{c}\text { Applicability to building materials } \\
\text { production }\end{array}$ \\
\hline 1 & $\begin{array}{l}\text { waste containing significant quantities } \\
\text { of toxic substances, the concentration } \\
\text { of which exceeds MPC }\end{array}$ & $\begin{array}{l}\text { cannot be used without special } \\
\text { cleaning measures }\end{array}$ \\
\hline 2 & $\begin{array}{l}\text { waste composed of a small amount of } \\
\text { heavy metals }\end{array}$ & $\begin{array}{l}\text { are recommended to be used for } \\
\text { materials production only at } \\
\text { baking technologies }\end{array}$ \\
\hline 3 & $\begin{array}{l}\text { concentration of emission does not } \\
\text { exceed MPC of carcinogenic (toxic) } \\
\text { substances and elements }\end{array}$ & $\begin{array}{l}\text { are recommended for next } \\
\text { evaluation level }\end{array}$ \\
\hline
\end{tabular}

Wastes from the first group cannot be used in manufacturing of building materials without any special decontamination and should be sent for disposal. If waste contains elements of heavy metals (second group), it might be recommend for usage in roasting technologies provided that raw mass has sufficient molten alloy for conservation (encapsulation) of heavy metals. The technology not only ensures reliable waste preservation, but also provides considerable increase in strength of ceramic material by heavy metal elements performing the role of heterogeneous catalysts promoting crystallization of melt and consequently increasing strength. Wastes from the third group are assessed on a finer scale. After a multi-level evaluation, waste is assigned a certain status [20-22]. 
Another source of indoor air pollution is polymers. If building materials are composed of polymers, degradation processes, inevitable in the course of operation, can lead to poor indoor climate. The list of polymeric materials used in construction contains more than 100 items. Polymers are used in manufacturing of wall finishing materials, heat-insulation materials, flooring, waterproofing materials, sealants, manufacturing of windows and door units, cladding panels, etc. The intensity of volatile toxin emission from them depends on the microclimate conditions of their application, i.e. temperature, humidity, air change rate, operation time. With increasing amount of polymeric materials in the air environment of residential premises and public buildings, the concentration of formaldehyde, phenol, benzene, ethyl benzene, xylene, ethyl acetate, toluene, butyl acrylate and other toxic substances expectedly increases as well.

Unfortunately, there are practically no regulations concerning environmental safety of home in terms of application of building materials. An exception is the State Standard GOST 30108-94 Building Materials and Products. Determination of Specific Effective Activity of Natural Radionuclides (with Amendments 1, 2), controlling the radioactivity of technogenic waste and radon emission from building materials. State examination at the designing stage only controls structural strength. Even if building inspection controls the quality of construction materials, they only consider conformity certificates. Monitoring indoor atmosphere at the commissioning stage is not obligatory. This problem needs to be addressed at the state level.

In the course of research, the authors classified information about emissions from basic groups of construction materials and maximum permissible concentrations (MPC) of harmful substances in indoor air. The method of evaluation of ecological safety and comfort of living accommodations in accordance with used construction and finish materials was proposed. Materials were grouped by sections "Construction Materials", "Construction-Heat-Insulation Materials", "Heat-Insulation Materials", "Finishing Materials", "Window and Door Materials." The study evaluated chemical composition of materials, a generic list of possible additives and their potential chemical emission into surrounding environment. Distribution of materials by their category of comfort was done according to five-point evaluation system: 5 - excellent (no toxic emission); 4 - very good (little emission, significantly below MPC); 3 - permissible (below MPC) 2 - permissible for areas of infrequent occupation; 1 - unacceptable for habitation.

The elaborated method of building materials evaluation gives an opportunity to put in perspective housing ecological parameters and to choice the least toxic ones. This information could be useful for private developers which control construction process more than housing buyers.

In order to enable construction companies to confirm the quality of the housing built and to provide citizens with complete information about their homes, the authors consider it necessary to create "Residential buldings ID", which, along with the assessment of planning concepts, design and engineering solutions, and the availability of infrastructural elements, should also evaluate the parameter of ecological safety of housing.

\section{Results}

The research yielded the following results:

- air pollution sources of residential premises were identified;

- building and finishing materials were recognized as the main source of pollution among them;

- regulatory framework on environmental security in the scope of construction materials was reviewed; 
- information about basic construction materials, emissions from them, and maximum permissible concentrations of harmful substances in indoor air was collected and classified;

- the obtained data were grouped by sections "Construction Materials", "ConstructionHeat-Insulation Materials", "Heat-Insulation Materials", "Finishing Materials", "Window and Door Materials."

- evaluation methodology of ecological safety of home was introduced.

\section{Discussion}

Construction of a modern apartment suggests using large amounts of materials. In the classical evaluation on the famous triad of Vitruvius - "Usefulness - strength - beauty» environmental component (usefulness) is at the first place for a certain reason. Aesthetic beauty of home should go hand in hand with its ecological safety. Therefore, it is vital to control building and finishing materials for creating healthy environment. The idea of saying 'no' to unsustainable building materials is very difficult to implement in practice. The authors ' methodology of evaluating the quality of materials for residential housing will let consumers objectively evaluate environmental performance of housing. The methodology is being constantly improved. This is due to the fact that it often happens so, that even without exceeding the maximum permissible concentrations of selected construction materials, indoor air quality leaves much to be desired. The thing is that the existing MPC regulations are calculated for each substance separately, without taking into account a combination of pollution sources. Therefore, in the course of further work the authors plan to develop a methodology for integrated assessment of housing contamination by toxic emissions from construction and finishing materials, as well as to investigate the variations of toxic emission volume and its intensity over time resulting from material degradation and aging.

\section{Conclusions}

Creating environmentally friendly living environment is a complex task that requires the interaction of hygienists, architects, builders and manufacturers of construction materials.

Improvements to the ecological safety of urban dwellings are possible if we:

- control the quality of air environment of premises put into operation at the state level;

- using the methods developed, carry out a toxicity assessment of the composite material components used in construction of residential buildings and the toxins released from synthetic materials;

- create "Residential buldings ID" containing information on the construction materials used;

- make an integral estimation of toxic emission from building materials.

\section{References}

1. V. K. Litskevich, Residential Construction 4, 24-26 (2011)

2. SANPIN 2.1.5.980-00 (Date of updating 12.02.2016) Hygienic Requirements for Surface Water Protection

3. SANPIN 2.1.7.1287-03 (Date of updating 12.02.2016) Sanitation and Disease Control Regulations for Soil Quality 
4. GOST 17.2.3.01-86 (Date of updating 06.04.2015) Nature protection. Atmosphere. Air quality control regulations for populated areas

5. GOST 17.1.2.04-77 (Date of updating 12.02.2016) Nature protection. Hydrosphere. Idices of state and regulations for valuation survey of fishery waters

6. SANPIN 2.1.2.1002-00 Sanitation and Disease Control Requirements for Residential Occupancies and Spaces (Date of updating: 01.02.2017)

7. MU 2.1.2.1829-04 Sanitary and Hygienic Evaluation of Polymer and Polymercotaining Building Materials and Structures for Residential, Public and Industrial Construction. Methodology Guidelines (Russian Ministry of Health, Russia, 2004)

8. SANPIN 2.1.2.729-99 Higienist requirements for safety polymeres building materials (Date of updating: 12.02.2016)

9. GN 2.1.6.1338-03 Maximum Permissible Concentration (MPC) of Pollutants in the Ambient Air of Populated Areas (as amended on 01.02.2017) (Russian Ministry of Health, Russia, 2003)

10. State Standard GOST 30494-2011 Residential and public buildings. Microclimate Parameters in Buildings (amended)

11. N. G. Chumachenko, A. Y. Zhigulina, Residential Construction 4, 21-23 (2011)

12. A. Y. Zhigulina, Traditions and Innovations in Construction and Architecture: Materials of the 69th All-Russian Scientific and Technical Conference on the results of $R \&$ $D, 2011$, 150-151 (Samara State University of Architecture and Civil Engineering, Samara, 2012)

13. A. Y. Zhigulina, Traditions and Innovations in Construction and Architecture: Materials of the 71st All-Russian Scientific and Technical Conference on the results of $R \&$ $D$, 2013, 384-385 (Samara State University of Architecture and Civil Engineering, Samara, 2014)

14. A. Y. Zhigulina, Traditions and Innovations in Construction and Architecture: Materials of the 69th All-Russian Scientific and Technical Conference on the results of $R \&$ $D, 2011,363-365$ (Samara State University of Architecture and Civil Engineering, Samara, 2012)

15. A. Y. Zhigulina, Traditions and Innovations in Construction and Architecture: Materials of the 70th Anniversary All-Russian Scientific and Technical Conference on the results of R \& D, 2012, 1, 337-338 (Samara State University of Architecture and Civil Engineering, Samara, 2013)

16. A. Y. Zhigulina, Town Planning 6, 46-48 (2013)

17. A. Y. Zhigulina, N. G. Chumachenko, Urban Construction and Architecture 3, $94-100$ (2015). DOI: $10.17673 /$ Vestnik. 2015.04.12

18. Accommodation: Comprehensive View, 32 (Moscow, 2001)

19. Scientific works of Samara School of Materials Scientists (Samara State University of Architecture and Civil Engineering, Samara, 2006)

20. N. G. Chumachenko, Ecology and Human Health. Proceedings of the VII All-Russian Congress, 201-203 (Samara, 2006)

21. N. G. Chumachenko, Urban Construction and Architecture 3, 112-116 (2011). DOI: $10.17673 /$ Vestnik.2011.01.22 